\title{
DIGITALCOMMONS
}

@WAYNESTATE —

Wayne State University

8-21-2014

\section{Termination of Parental Rights for Parents With Substance Use Disorder: For Whom and Then What?}

Jun Sung Hong

Wayne State University, fl4584@wayne.edu

Joseph P. Ryan

University of Michigan

Pedro M. Hernandez

Winston Salem State University

Suzanne Brown

Wayne State University

\section{Recommended Citation}

Hong, J.S., Ryan, J.P., Hernandez, P.M., \& Brown, S. (2014). Termination of parental rights for parents with substance use disorder: For whom and then what? Social Work in Public Health, 29(6), 503-517. DOI 10.1080/19371918.2014.884960

Available at: http://digitalcommons.wayne.edu/soc_work_pubs/31 
NOTICE IN COMPLIANCE WITH PUBLISHER POLICY: This is the author's final accepted manuscript version, post-peer-review, of an article published by the Taylor \& Francis Group in Social Work in Public Health on August 21,2014 , available online at http://dx.doi.org/10.1080/19371918.2014.884960 


\title{
Termination of Parental Rights for Parents With Substance Use Disorder: For Whom and Then What?
}

\author{
Jun Sung Hong' ${ }^{1}$, Joseph P. Ryan², Pedro M. Hernandez ${ }^{3}$, Suzanne Brown ${ }^{1}$
}

\begin{abstract}
The purpose of this study is to investigate the correlates of termination of parental rights (TPR) for parents with substance use disorder (SUD) and to determine what happens with regard to permanency once a TPR decision is made. Bivariate techniques and hierarchical non-linear modeling are used. Parents of older youth, boys, and Hispanics were less likely, while parents who failed to make progress in substance use treatment and parenting skills are more likely to experience TPR. At follow up, $85 \%$ of the children were adopted, $7 \%$ remained in a substitute care settings, and $7 \%$ were reunified with their parents. Concerns remain for children without a permanent home setting.
\end{abstract}

\section{KEYWORDS}

child welfare; parenting;

permanency; substance

abuse; termination of

parental rights

\section{Introduction}

According to the U.S. Department of Health and Human Services (2008), over 469,000 parents of children in foster care lost their custodial rights from 2002 to 2007, and many of these parents struggled with substance use. Parents with substance use disorder (SUD) in particular are at a heightened risk of losing their custodial rights (Marcenko, Kemp, \& Larson, 2000) due to higher rates of maltreatment substantiation (Gregoire \& Schultz, 2001; Semidei, Radel, \& Nolan, 2001; Sun et al., 2001). Their children frequently experience out-of-home care placement (Maluccio \& Ainsworth, 2003; U.S. Department of Health and Human Services, 1999a, b) and transitions while in foster care (Smith et al., 2007). Efforts have been underway to improve the coordination of treatment services to parents with SUD and their children (Grella, Hser, \& Huang, 2006). However, little has been known about the characteristics of parents with SUD whose parental rights were terminated and their children who are involved in the child welfare system (Grella et al., 2006).

A handful of studies shed light on the association between age, gender, and race/ethnicity of the child, and termination of parental rights (TPR) for parents with substance use disorder. Studies document that younger children experience TPR and adoption more frequently, while older children are more likely to be reunified with their biological parents (Connell et al., 2006; Courtney et al., 1997; Vogel, 1999; Zinn \& Slowriver, 2008). This is not surprising as caseworkers are more likely to be concerned with the safety and well-being of younger children, and there is greater availability of kinship care arrangements for younger children (Connell et al., 2006). Research findings also consistently suggest that racial/ethnic minority children (particularly African Americans) and boys are more likely than white children and girls to be overrepresented in the child welfare system (Anyon, 2011). African American children are significantly more likely than children of other racial/ethnic groups to be removed from their homes once a report of abuse is confirmed (Hill, 2007; Lu et al., 2004; Wulczyn, 2003; Wylczyn, Hislop \& George, 2000; Wulczyn \& Lery, 2007). African American parents are more likely to experience TPR than white parents (Kapp, 2001; Noonan \& Burke, 2005), and their children wait longer in foster care for permanent placements (Zinn \& Slowriver, 2008), face barriers to family reunification, and experience longer delay in reunification than white

\footnotetext{
${ }^{1}$ School of Social Work, Wayne State University; ${ }^{2}$ School of Social Work, University of Michigan; ${ }^{3}$ Winston Salem State University Corresponding author: Jun Sung Hong, School of Social Work, Wayne State University, Detroit, MI 48202 Email: fl4684@wayne.edu
} 
children (Connell et al., 2006; Courtney et al., 1997; Davis, Landsverk, \& Newton, 1997; Vogel, 1999).

\section{Parental Substance Abuse}

Parental rights are terminated in cases where the parents' substance use disorder compromises their parenting ability (Miller \& Flaherty, 2000) due to physical and mental impairments; domestic violence; frequent arrests, incarceration, and court dates; and estrangement from family and related supports. Parents with substance use disorders also experience other cooccurring problems that affect their parenting practices, such as unemployment, homelessness, and high levels of stress, all of which can result in child welfare involvement (National Center on Addiction and Substance Abuse, Columbia University, 2005). Empirical research also documented that many families involved with the child welfare system frequently struggle with parental substance use disorders (Jones, 2005; Magura \& Laudet, 1996; Young, Gardner, \& Dennis, 2000).

\section{Parental Incarceration}

Parental incarceration is another significant risk factor for TPR, as increasing numbers of children of incarcerated parents have been involved in the foster care system (Johnson \& Waldfogel, 2002). Parental incarceration has been linked to an increased likelihood of TPR, especially if the incarcerated parent is the mother (Gentry, 1998). Although incarceration itself cannot be used as a determining factor for TPR (Seymour \& Finney-Hairston, 2001), incarcerated parents lose their custodial rights because they are unavailable for their children and there is a lack of specific state policies for placing children (Johnson \& Waldfogel, 2002). In addition, approximately 75\% of prison inmates reported having a lifetime prevalence of a substance related disorder; among these, over 50\% were diagnosed with substance use disorder during the 30 days prior to incarceration (Peters et al., 1998). Considering the strong association with parental substance use disorders, incarceration is a fundamental risk factor in TPR (Meyer et al., 2010).

\section{Treatment Rate Progress}

Treatment progress in relation to substance abuse, mental health, parenting skills deficits, housing, and domestic violence can especially determine whether a parent maintains or loses their custodial rights. According to the Adoptions and Safe Families Act, parents with substance use disorder have 12 to 18 months to make progress or the process of terminating their parental rights will be initiated. In Illinois, there must be sufficient evidence that the parent shows no signs of improvement in treatment progress before proceeding with TPR (Miller \& Flaherty, 2000). It is essential to investigate outcomes of treatment progress for parents with substance use disorder who are involved in the child welfare system.

Parental Substance Misuse. In response to the needs of parents with substance use disorder, there has been increasing attention to improving services and ensuring that these parents have access to timely and appropriate services (Larsen, 2000). A statewide longitudinal study by Green, Rockhill, and Furrer (2007) found that when mothers entered substance-abuse treatment more quickly, spent more time in treatment, or completed at least one treatment, their children spent fewer days in foster care and were more likely to be reunified with them. Interestingly, studies have frequently focused on treatment completion which judges use as a key factor in their decisions (Karoll \& Poertner, 2002). For instance, Smith (2003) found from a sample of 159 families with substance use disorder with at least one child in substitute care that treatment completion increased the likelihood of reunification. In contrast, other studies found that despite completing substanceabuse treatment, parents with substance use disorder were unlikely to gain custody of their children (Gregoire \& Shultz, 2001), and treatment compliance did not increase the likelihood of re-entry into the child welfare system (Rittner \& Dozier, 2000). Despite these findings, substance-abuse treatment remains a significant factor in the court decision-making process concerning TPR and reunification (Child Welfare Information Gateway, n.d.). Many jurisdictions have developed specialized programs to combine child welfare, substance-abuse, and court services to support reunification.

Mental Health. Considering that substance use frequently co-occurs with mental illness (Kessler et al., 1997), parents with substance use disorder and mental illness may experience involuntary TPR. In some states, TPR for mentally ill parents is on a case-by-case basis, while others have specific TPR measures for mentally ill parents (Shelton \& Smith, 1990). Wattenberg, Kelly, 
and $\operatorname{Kim}(2001)$ report that over $80 \%$ of mothers who lost their custodial rights have dual/multiple disorders, most notably, serious mental illness. Sixty-three percent of their children had not achieved permanency; 35\% were being prepared for adoption; and two remained in long-term kinship foster care. Burton, Jr. (1990) also found that 20 states statutorily remove children from the custody of mentally ill parents because of stigma, and a lack of social support and employment. Caseworkers and the courts frequently argue that parents diagnosed with mental illness are incapable of assuming caregiving roles (Ackerson, 2003), and their children are removed from their custody as a result (Burton, Jr., 1990). Caseworkers, child welfare professionals and the courts may also assume that caregiving is devalued by parents with mental illness (Ackerson, 2003), although study findings indicate otherwise (e.g., Mowbray, Oyserman, \& Ross, 1995).

Discriminatory practices in the court proceedings concerning parents with mental illness can also increase the likelihood of TPR for mentally ill parents (McConnell \& Llewellyn, 2000). Mental illness has been empirically linked to maltreatment (e.g., Sidebotham, Golding, \& The ALSPAC Study Team, 2001; Walsh, MacMillan, \& Jamieson, 2003), and mentally ill parents frequently encounter involuntary TPR if they are perceived as a threat to their child's health or safety (Bernstein, 1990-1991). However, they can also lose their parental rights even if there is little or no evidence of risk of harm to the child.

Parents with substance use disorder and mental illness are significantly at risk of TPR (Meyer et al., 2010), and effective treatment is critical. However, mentally ill parents who are attempting to regain custody of their children encounter barriers to treatment progress, such as debilitating side effects of medication, which can prolong time of treatment and conflicts with permanency planning time frames (Risley-Curtiss et al., 2004).

Parenting Skills. Treatment rate progress in the development of parenting skills can determine whether parents with substance use disorder lose their parenting rights. Parents who fail to demonstrate adequate parenting skills may lose their parental rights, although there is little evidence to indicate that parents involved in the child welfare system have inadequate parenting skills. For instance, Barth et al. (2005) found that only $33 \%$ of the caregivers who lost their custodial rights were identified by child welfare professionals as having poor parenting skills. In sum, parental competence needs to be determined by whether parents with substance use disorders can provide a safe and stable home environment for their children (Steinhauer, 1991).

Housing. Housing and homelessness are also associated with the likelihood of TPR for parents with substance use disorder, which is not surprising given that substance misuse frequently co-occurs with homelessness (Connell et al., 2006; Noonan \& Burke, 2005; Semidei, Radel, \& Nolan, 2001), which increases TPR risk. Homelessness is recognized as a ground for involuntary TPR; parents who are homeless are unable to meet their child's need for a permanent, safe, and nurturing home environment. Homelessness is also a significant barrier to reunification. For example, Barrow and Laborde (2008) found that homeless mothers who lost custody of their child encountered a number of obstacles whenever they attempted to reunify with their children. These mothers reported being under a tremendous amount of pressure from the shelter, treatment center, child welfare agencies, and family court judges to obtain housing in addition to successfully completing substance abuse treatment.

Domestic Violence. Given that domestic violence places children at a heightened risk for maltreatment (see Osofsky, 2003, for a review), parents who experience domestic violence are likely to have their parental rights terminated for substantiated maltreatment (Kohl et al., 2006; Wekerle et al., 2007). Several states have passed legislation which makes children's exposure to domestic violence a form of criminal child abuse (Kantor \& Little, 2003). Victimized mothers frequently lose custody of their children for their perceived failure to protect their children from domestic violence exposure, even when the child was not maltreated (Lemon, 1999). Studies have also established that domestic violence is a common occurrence among parents with substance use disorder (e.g., Conners-Burrow, Johnson, \& WhitesideMansell, 2009), which significantly increases their risk of involuntary TPR. Therefore, domestic violence treatment progress is imperative.

\section{Post-TPR}

In $2007,51,401$ children of parents whose parental rights had been terminated were adopted from the 
public foster care system (CWLA, n.d.). The remaining children were also placed in pre-adoptive home, group home, institution, or supervised independent living (Noonan \& Burke, 2005). Children placed with a preadoptive family prior to TPR were adopted within 11.63 months, and those who were not placed in a preadoptive family were adopted on average of 20.47 months after their parents lost their custodial rights (Cushing \& Greenblatt, 2009). Regrettably, 133,818 children were placed in a permanent home and were awaiting adoption (CWLA, n.d.). Although placing a child in a permanent home has been the longstanding goal of TPR, adoption may be unlikely for some children due to a shortage of adoptive homes, the age of the child, and the severity of the child's behavioral or mental health problems (Floria, 2008). Indeed, children separated from their biological families find themselves transitioning from one foster home to another without a sense of stability (Schneider \& Phares, 2005).

\section{Study Purpose And Hypotheses}

Despite indication that parents with substance use disorder are at a heightened risk of TPR, empirical research is relatively limited. To fill the current research gap, we investigate the correlates of TPR for parents with substance use disorder and their treatment rate progress in the domains of substance use, mental health, parenting skills, housing issues, and domestic violence. We also explore what happens to children's placement one year subsequent to TPR. We hypothesize that TPR is more likely for parents of younger and racial/ethnic minority children, and for parents with substance use disorder who are incarcerated. We also hypothesize that TPR is less likely for parents who comply with the court mandated treatment progress.

\section{Methods}

\section{Sample}

The sample includes mothers enrolled in the Illinois Title IV-E AODA Waiver Demonstration Project as of June 30, 2004 and their children. The total sample for this study is 3,339 , consisting of 1,179 mothers and the 2,160 children of these mothers in the Demonstration Project. The mean age of children in the sample is 3.51 years old. The Project utilizes an experimental design to test a model of intensive case management in the form of a recovery coach designed to increase access to substance use services, improve substance use treatment outcomes, reduce the length of time in substitute care placements, and increase the rates of family reunification. Eligible families for this demonstration include foster cases opened on or after April 28, 2000 in Cook County.

To qualify for the project, mothers with substance use disorder must have been referred to the Juvenile Court Assessment Program (JCAP) at the time of their temporary custody hearing or at any time within 90 days subsequent to the hearing. JCAP provides substance use assessments for adults and is located on site at the Juvenile Court Building, which provides easy access for parents who had their parental rights terminated and those who are in need of an assessment to determine if a referral to substance use treatment is appropriate and necessary (Ryan et al., 2008). The criteria are established by the American Society of Addiction Medicine, which specifies the following four levels of care: (1) outpatient, (2) intensive outpatient/partial hospitalization, (3) residential treatment, and intensive inpatient treatment (O’Toole et al., 2004).

JCAP staff members conducted substance use screenings and referred families for substance-abuse treatment, and the caseworkers completed service plan forms throughout the treatment process. JCAP conducts approximately 1,000 assessments within the court building annually, and of these 1,000 referrals about $61 \%$ result in referrals to treatment providers. Of the clients indicated for treatment, approximately 50\% were eligible for the IV-E AODA project because they met the following criteria: (1) Cook County Illinois Case, (2) Temporary Custody of their child(ren) had been granted to DCFS, and (3) Parents were assessed at JCAP within 90 days of the Temporary Custody Hearing (Ryan et al., 2008). This study was approved by the Institutional Review Boards at the University and the Illinois Department of Alcohol and Substance Abuse.

\section{Measures}

We utilized two sources of data: JCAP and the Illinois DCFS. For the JCAP data, licensed clinicians conducted a thorough computerized assessment to determine whether or not a client requires a treatment recommendation and referral. JCAP data include a variety of socio-demographic assessment related information on the child, such as age, gender, and 
race/ethnicity; and on incarceration of at least one parent at initial JCAP assessment, presence of cooccurring problems, treatment progress for substance use, mental health, parenting skills deficits, housing, domestic violence (as rated by caseworkers), and current alcohol and drug use. The treatment progress was defined as 'mixed' (i.e., only one parent making significant progress) or 'completed' (i.e., both parents making significant progress).

For statistical analyses purposes, the child demographic variables, 'female' and 'African American' were treated as reference variables. For treatment progress, 'not making significant treatment progress' was treated as the reference variable. DCFS includes data on when TPR was reached. For the purposes of the analysis, only children who reached TPR within three years of their assignment to the AODA Waiver Demonstration Project were used as an outcome. Children who did not reach TPR within three years of their assignment to the Project were excluded altogether from the analysis.

The percentages, means, and the standard deviations for the samples are presented in Table 1. The average number of days in placement was 1,377 days. The average age of the child at JCAP was 3.51 years of age. Males comprised over half $(54.7 \%)$ of the sample. For race/ethnicity, $79.7 \%$ were African Americans, followed by $12.7 \%$ white and $7.6 \%$ Hispanic. Our findings also indicate that $13.6 \%$ of the parents had their parental rights terminated within three years, and $72.7 \%$ were assigned to the AODA experimental group. Slightly over a quarter $(21.6 \%)$ of families had at least one parent incarcerated at initial JCAP assessment, and over one-third $(37.7 \%)$ had used cocaine, followed by $17.7 \%$ alcohol, $15.4 \%$ marijuana, and $2.9 \%$ other drugs. Twenty-nine percent had mixed rate, while $21.4 \%$ had completed rate of progress for substance use treatment. Almost one-quarter $(19.8 \%$ ) had mixed rate and 31.0\% had completed rate of progress for mental health treatment. Twenty-six percent had mixed rate and $27.6 \%$ had completed rate of progress for parenting skills treatment. Almost one-quarter $(19.5 \%)$ had mixed rate and $31.3 \%$ had completed rate for treatment with regards to housing. And finally, $12.6 \%$ had mixed rate and $31.4 \%$ had completed rate of treatment for domestic violence.

\section{Analysis}

This study relies on two sampling units: the first represents children associated with the AODA Waiver

Table 1. Means (Standard Deviation) or Percentages of the Sample $(N=3,339)$

Variable

$\%$

Child characteristics

TPR within 3 years

Days in placement (1-3106)

$\mathrm{M}=1376.57$; $\mathrm{SD}=663.86$

Factors associated with TPR

Socio-demographic characteristics

Age at JCAP (0-19)

$\mathrm{M}=3.51$;

$\mathrm{SD}=4.46$

Gender

Male

Race/ethnicity

African American

79.7

White

12.7

Hispanic

7.6

Parental characteristics

Factors associated with TPR

Substance abuse

Alcohol

17.7

Cocaine

37.7

Marijuana

15.4

Other drugs

2.9

AODA treatment group

72.7

Incarceration at initial JCAP

21.6

Treatment rate progress

Substance abuse

Mixed

28.9

Completed

21.4

Mental health

Mixed

19.8

Completed

Parenting skills deficit

Mixed

26.2

Completed

Housing issues

Mixed

19.5

Completed

Domestic violence

Mixed

Completed 
Demonstration Project and the second represents families associated with each child. Although cross-level inferences can be made using a variety of approaches, hierarchical non-linear models were designed specifically for cross-level inferences that link the characteristics of the individuals to the characteristics of the groups in which they are nested (Raudenbush \& Bryk, 2002). The variable domains were entered into two-level nested models, where children (Level 1) were nested within their mothers (Level 2). At the child level, the hierarchical non-linear model estimates the relationship between days in placement and children's socio-demographic characteristics (i.e., age at JCAP, gender, race/ethnicity), and TPR. At the parents' level, the hierarchical non-linear model estimates the relationship between parental characteristics, treatment progress/completion, and TPR. We utilized bivariate techniques and hierarchal non-linear modeling via HLM software to examine the factors associated with TPR. We also focus on two outcomes of interest: TPR within three years, and the placement setting of children 12 months subsequent to TPR. The regression models account for child and parental characteristics, and treatment progress across the following domains: substance use, mental health, parenting skills, housing, and domestic violence.

\section{Results}

Table 2 reports the results of the predictors for TPR. The child characteristics of age at JCAP, gender, and race/ethnicity were all significantly associated with TPR. Parents of older children (OR $=.87, p<.00)$, boys $(\mathrm{OR}=.92, p<.05)$ and Hispanics $(\mathrm{OR}=.46$, $p<.01)$ were less likely to be at risk for TPR. In terms of parental characteristics, only cocaine use was positively correlated with TPR, while AODA treatment was negatively correlated with TPR. Parents who used cocaine were 1.64 times more likely to experience TPR $(p<.01)$, while those in the AODA group were less likely $(\mathrm{OR}=.60, p=.02)$ to experience TPR. Two types of treatment progress were predictive: parents with substance use treatment progress evaluated as 'mixed' $(\mathrm{OR}=.41, p<.00)$ and parenting skills progress rate 'completed' $(\mathrm{OR}=.53, p=.04)$ were negatively associated with TPR.

Regarding the outcomes of TPR, we investigated the placement location of children 12 months subsequent to TPR $(n=294)$. At this observation point,
Table 2. Child Characteristics, Parental Characteristics, and Treatment Rate Progress

\begin{tabular}{|c|c|c|c|}
\hline Variable & T-Ratio & $p$ & O.R. \\
\hline \multicolumn{4}{|l|}{ Child characteristics } \\
\hline \multicolumn{4}{|l|}{ TPR within 3 years } \\
\hline Days in placement & -14.35 & $0.00 * *$ & 1.00 \\
\hline \multicolumn{4}{|l|}{$\begin{array}{l}\text { Socio-demographic } \\
\text { characteristics }\end{array}$} \\
\hline $\begin{array}{l}\text { Age at JCAP (0- } \\
19)\end{array}$ & -5.43 & $0.00 * *$ & 0.87 \\
\hline \multicolumn{4}{|l|}{ Gender } \\
\hline Male & -0.76 & $0.05^{*}$ & 0.92 \\
\hline \multicolumn{4}{|l|}{ Race/ethnicity } \\
\hline White & 0.34 & 0.73 & 1.08 \\
\hline Hispanic & -2.68 & $0.01 * *$ & 0.46 \\
\hline
\end{tabular}

Parental characteristics

Factors associated with TPR

Substance abuse

Alcohol

Cocaine

Marijuana

Other drugs

AODA

Treatment

group

Incarceration at

initial JCAP

$-2.680 .01^{* *}$

0.46

Treatment rate progress

Substance abuse

Mixed

Completed

$-3.72$

0.00 **

0.41

Mental health

Mixed

$-1.53$

0.13

0.62

Completed

0.98

0.33

1.29

Parenting skills deficit

Mixed

$-0.42$

0.67

0.90

Completed

1.34

0.18

1.40

Housing issues

Mixed

$-2.03$

$.04 *$

0.53

Completed

$-1.51$

0.13

0.66

Domestic violence

Mixed

$-0.93$

0.35

0.78

Completed

$-1.03$

0.31

0.74

0.69

0.49

1.19

$p<.05 ;{ }^{* *} p<.01$ 
$85.4 \%(n=251)$ were adopted, $7.1 \%(n=21)$ were placed in foster care, $7.1 \%(n=21)$ were reunified with their biological parent(s), and $0.3 \%(n=1)$ were placed in a residential setting (e.g., group home) (see Table 3 ).

In terms of race/ethnicity, there was little difference in placement location subsequent to TPR between African American and white children. For African American children $(n=238), 86.1 \%(n=205)$ were adopted, while $7.1 \%(n=17)$ were placed in foster care and $6.1 \%(n=16)$ were reunified with their biological parent(s) (see Table 4). For white children $(n=45)$, $84.4 \%(n=38)$ were adopted, followed by $8.9 \%(n=4)$ in foster care, $4.4 \%(n=2)$ reunified with parent(s), and $2.2 \%(n=1)$ in a residential setting. For Hispanic children $(n=11), 72.7 \%(n=8)$ were adopted, and $27.3 \%(n=3)$ were placed in the home of a relative (see Table 4).

Table 3. Post-TPR Placement Location $(N=294)$

\begin{tabular}{lrr} 
Placement Location & $N$ & $\%$ \\
\hline Adopted & 251 & 85.4 \\
Foster care & 21 & 7.1 \\
Reunification (w/ biological parents) & 21 & 7.1 \\
Residential setting & 1 & 0.3 \\
\hline
\end{tabular}

Table 4. Post-TPR Placement Location by Race and Ethnicity $(\mathrm{N}=283)$

\begin{tabular}{lrr} 
Placement Location & $N$ & $\%$ \\
\hline African American & 238 & \\
Adopted & 205 & 86.1 \\
Foster Care & 17 & 7.1 \\
Reunification & 16 & 6.1 \\
White & 45 & \\
Adopted & 38 & 84.4 \\
Foster Care & 4 & 8.9 \\
Reunification & 2 & 4.4 \\
Residential & 1 & 2.2 \\
Hispanic & 11 & \\
Adoption & 8 & 72.7 \\
Home of a Relative & 3 & 27.3 \\
\hline
\end{tabular}

\section{Discussion}

This study highlights the importance of research on TPR for parents with substance use disorder. Consistent with previous research (e.g., Connell et al., 2006), our findings suggest that parents of older children are less likely than parents of younger children to experience TPR. TPR is unlikely to be filed when adoption is not the permanency goal of the child, and older children are less likely to be adopted than younger children. Boys are significantly more likely to be physically abused than girls (Hershkowitz, Lamb, \& Horowitz, 2007; Sobsey, Randall, \& Parrila, 1997), putting them at risk for child welfare involvement, our results indicate that boys are significantly less likely than girls to be removed from their home. Inconsistent with other studies, which suggest that African American children were overrepresented in the child welfare system (Anyon, 2011) and TPR cases (SagatunEdwards, Saylor, \& Shifflett, 1995) and less likely to be reunified with their parents (Connell et al., 2006; Courtney et al., 1997; Davis, Landsverk, \& Newton, 1997; Vogel, 1999; Zinn \& Slowriver, 2008), we found that mothers of African American children were no more likely than white children to experience TPR, and Hispanic children were even less likely than African American and white children to be removed from their homes. It appears that TPR decisions are largely based on lack of treatment progress, regardless of race/ethnicity.

Concerning parental substance use, cocaine use increased the risk and participation in AODA treatment groups decreased the risk of TPR. This is not surprising because courts are likely to treat those who participated in substance use treatment differently from those who did not participate in treatment. Further, mothers' compliance with court-ordered substance use treatment can increase their likelihood of reunification with their children (Rittner \& Dozier, 2000). In addition, mothers whose substance use treatment progress was 'mixed' were less likely to experience TPR compared to mothers who made no significant progress. This finding is not surprising given that the courts assess mothers' potential for recovery before proceeding with TPR (Miller \& Flaherty, 2000).

In this study, we also examined the treatment rate progress for parenting skills of mothers with substance use disorder involved in TPR. We found that mothers who completed parenting skills treatment were also less 
likely to experience TPR and were more likely to reunify with their children. This is not surprising, considering that mothers who fail to demonstrate adequate parenting skills and competence are likely to lose their parental rights although there has been little evidence of parenting skills deficits in mothers whose parental rights were terminated.

Although the majority of the children in our study were adopted or reunified with their biological parents, about $7 \%$ were not placed in a permanent home setting even after 12 months subsequent to TPR. About $7 \%$ of African American children and 11\% of white children were placed in a temporary setting (e.g., foster home) after they were removed from their home. Interestingly, $27.3 \%$ of Hispanic children resided with a relative, which may or may not be a permanent setting. Older children in particular were less likely to achieve permanency, as they were less likely than younger children to be adopted. Also, foster families might hesitate to adopt or assume guardianship because they might fear losing financial assistance available to children in foster care, which is critical to meeting the children's needs (U.S. Department of Health and Human Services, n.d.). For these reasons, posttermination planning for older youth should include living arrangements other than adoption, such as specialized care, kinship legal guardianship, or independent living (Floria, 2008).

\section{Practice Implications}

The growing numbers of children placed into out-ofhome care due to parental substance use have led to greater demands for a more accessible substance use treatment (O'Flynn, 1999). Moreover, coordination of services for parents with substance use disorder who are simultaneously involved in the criminal justice system and receiving services for mental health, housing, and parenting might be daunting, given the complexities of interacting with different service delivery systems (Grella et al., 2006).

Nevertheless, findings from this study have practice implications for child welfare professionals working with parents with substance use disorder and their children. As previously mentioned, parents of older children are significantly less likely to experience TPR because older children are less likely to find permanent homes than younger children. The difficulty in finding a suitable family living arrangement for older children has been a pressing concern for professionals and social service agencies (McMillen et al., 2004). It is imperative that the child welfare system make all attempts to improve older children's transition to alternative living arrangements, such as independent living, group homes, or residential setting by providing assistance in locating housing and employment, safety net, and greater access to health and mental health services (Courtney et al., 2001).

Because children of mothers with substance use disorder are significantly likely to experience out-ofhome placements, there is a critical need for joint collaborative efforts between child welfare service providers and substance use treatment providers (Sun et al., 2001). Historically, substance use and child welfare service delivery systems have different goals, orientations, and organization (Karoll \& Poertner, 2002), which led to fragmentation and lack of coordination of services and case planning (Grella et al., 2006; Reed \& Karpilow, 2002). Given the significant association between parental substance use disorder and child welfare involvement, both service providers have increasingly been called upon to provide integrated services for parents with substance use disorder involved in the child welfare system (McAlpine, Marshall, \& Doran, 2001). One such example is the Montgomery County, Maryland initiative, in which the Child Welfare Services and Adult Addiction Services joined forces to develop an initiative to meet the needs of parents with substance use disorder involved in the child welfare system. The initiative has been designed to address the needed services for parents with substance use disorder, foster client participation, and promote client motivation (McAlpine et al., 2001). Family Dependency Treatment Courts (FDTC) is another viable intervention for parents with substance use disorder who are involved in the child welfare system. FDTC, which began in Reno, Nevada in 1985, seeks to provide a safe environment for the children while providing substance use treatment for the parents (Wheeler \& Fox, Jr., 2006). The FDTC approach has resulted in collaborations between the agencies and clients' compliance with substance use treatment necessary to improve children's well-being (Wheeler \& Fox, Jr., 2006).

And finally, because parenting practices have a profound impact on child development and behavior, it is not surprising that lack of parenting skills can increase TPR risk for mothers with substance use disorder. However, few substance use treatment 
programs provide "parenting" services for parents with substance use disorder (Grella \& Greenwell, 2004). A case in point, Smith and Marsh (2002) found that less than half of the women in a specialized substance use treatment reported receiving "family counseling" services, although the program was designed specifically for mothers with substance use disorder who are involved in the child welfare system. Thus, it is essential that substance use treatment for parents with substance use disorder aims to improve parenting skills and to develop coordination of treatment with the child welfare system (Jansson, Svikis, \& Beilenson, 2003). Child welfare professionals also need to assess parenting skills and the quality of parent-child relationships in the home (Azar \& Benjet, 1994). For parents with substance use disorder with demonstrated lack of parenting skills, practitioners can assist them by referring them to programs that are designed to strengthen their parenting skills.

Previous literature on parenting supports multiple intervention pathways for improving parenting behaviors in parents with substance use disorders. Behavioral skills training interventions have been used with mothers with substance use disorders to increase positive parenting behaviors thereby reducing externalizing behaviors in children (Ashery, Robertson, \& Kumpfer, 1998). However, while such interventions have shown effectiveness in changing behaviors, they have had little on the quality of the parent/child relationship (Suchman, Mayes, Conti, Slade, \& Rounsaville, 2004). Suchman and colleagues (2004) have incorporated an attachment theory perspective into parenting interventions with this population with positive results in both domains-behavioral skills and quality of parent/child relationship. Social support for parenting may be another important avenue for intervention with parents with substance use disorders. Previous studies have established a link between positive social support, both perceived and received, and better parenting skills (Kotchick, Dorsey, \& Heller, 2005); and between social support and frequency of parent-child interactions (Green, Furrer, \& McAllister, 2007). However, it is important to note that no social support parenting interventions have been developed for substance using parents, and current parenting interventions have been developed specifically with mothers in mind and with little consideration to interventions for fathers.

\section{Limitations}

This study is not without any limitations. Information was exclusively derived from the caseworkers' perspectives rather than parents' perspectives about the services received. As a result, services administered consistently exceed client estimates of services received (Allison, Hubbard, \& Rachal, 1995; Gerstein et al., 1997). Effectiveness of the services can be determined when clients specify the nature of their problems and receive appropriate services that meet their needs (Smith \& Marsh, 2002). In addition, our study did not include any fidelity measures. That is, we are aware which families were assigned to the treatment plan, but we cannot determine how the treatment plan varied across families in the experimental condition (Ryan et al., 2008). Such information is necessary for identifying specific program components most responsible for targeted changes. Future studies of treatment plans for parents with substance use disorder can benefit from fidelity assessment.

\section{Conclusion}

Despite the limitations discussed, our study also has a number of strengths. First, our findings highlight the importance of elucidating the correlates of TPR and treatment progress of parents with substance use disorder. For the most part, TPR has been examined from a legal perspective, and empirical research on TPR has been scant. Thus, much is unknown about the characteristics and correlates of TPR, and most specifically among parents with substance use disorder (Choi \& Ryan, 2006). Our study contributes to both substance use and child welfare research, and the AODA Waiver Demonstration Projects is a viable resource for such endeavors.

The Adoption and Safe Families Act of 1997 mandated that the goal of the child welfare system is to make a determination of permanent placement as early as possible for children who were removed from their home (Grella et al., 2006). However, it is also necessary to understand whether TPR is indeed in the best interest of the child as well as judicial oversights postTPR. A case in point is Tyler et al.'s (1997) study, which compared 44 mothers with substance use disorder who retained custody of their children with 23 who lost custody. Their findings indicate that children under birth mothers' care displayed better cognitive ability than those separated from their birth mother. Our 
study raises important questions about who is likely to experience TPR and who is likely to be placed in a permanent home subsequent to TPR. Only rigorous longitudinal developmental studies will shed light on the costs and benefits of TPR.

\section{References}

Ackerson, B. J. (2003). Parents with serious and persistent mental illness: Issues in assessment and services. Social Work, 48, 187-194.

Allison, M., Hubbard, R. L., \& Rachal, J. V. (1995). Treatment process in methadone, residential, and outpatient drug free programs. Rockville, MD: National Institute of Drug Abuse.

Ashery, R. S., Robertson, E. B., \& Kumpfer, K. L. (1998). Drug abuse prevention through family interventions. NIDA Research Monograph 177. Bethesda, MD: National Institute on Drug Abuse.

Azar, S. T., \& Benjet, C. L. (1994). A cognitive perspective on ethnicity, race, and termination of parental rights. Law and Human Behavior, 18, 249-268.

Barrow, S. M., \& Laborde, N. D. (2008). Invisible mothers: Parenting by homeless women separated from their children. Gender Issues, 25, 157-172.

Barth, R. P., Landsverk, J., Chamberlain, P., Reid, J. B., Rolls, J. A., Hurlburt, M. S....Kohl, P. L. (2005). Parent-training programs in child welfare services: Planning for a more evidence-based approach to serving biological parents. Research on Social Work Practice, 15, 353-371.

Bernstein, P. (1990-1991). Termination of parental rights on the basis of mental disability: A problem in policy and interpretation. Pacific Law Journal, 22, 1155-1183.

Burton, Jr., V. S. (1990). The consequences of official labels: A research not on rights lost by the mentally ill, mentally incompetent, and convicted felons. Community Mental Health Journal, 26, 267276.

Child Welfare League of America (n.d.). The nation's children 2010. Retrieved September 3, 2010, from

http://www.cwla.org/advocacy/statefactsheets/2010/nationalfactshee t10.pdf

Choi, S., \& Ryan, J. P. (2006). Completing substance-abuse treatment in child welfare: The role of co-occurring problems and primary drug of choice. Child Maltreatment, 11, 313-325.

Connell, C. M., Katz, K. H., Saunders, L., \& Tebes, J. K. (2006). Leaving foster care: The influence of child and case characteristics on foster care exit rates. Children and Children Services Review, 28, 780-798.

Conners-Burrow, N. A., Johnson, B., \& Whiteside-Mansell, L. (2009). Maternal substance abuse and children's exposure to violence. Journal of Pediatric Nursing, 24, 360-368.

Courtney, M. E., Piliavin, I., \& Wright, B. E. (1997). Transitions from and returns to out-of-home care. Social Service Review, 71, 652-667.

Courtney, M. E., Piliavin, I., Grogan-Kaylor, A., \& Nesmith, A. (2001). Foster youth transitions to adulthood: A longitudinal view of youth leaving care. Child Welfare, $L X X X, 685-717$.

Cushing, G., \& Greenblatt, S. B. (2009). Vulnerability to foster care drift after the termination of parental rights. Research on Social Work Practice. Online First, published on February 23, 2009 as doi:10.1177/1049731509331879

Davis, I., Landsverk, J., \& Newton, R. (1997). Duration of foster care for children reunited within the first year of care. In J. Berrick,
R. Barth, \& N. Gilbert (Eds.), Child welfare research review (vol. 2, pp. 272-293). New York: Columbia University Press.

Floria, S. (2008). More good than harm: Legal orphans and the New Jersey Post-Termination Project. Juvenile and Family Court Journal, 59, 1-13.

Gentry, P. M. (1998). Permanency planning in the context of parental incarceration: Legal issues and recommendations. Child Welfare, 77, 543-559.

Gerstein, D. R., Datta, A. R., Ingels, J. S., Johnson, R. A., Rasinski, K. A., Schildhouse, S., et al. (1997). NTIES: National Treatment Improvement Evaluation Study, final report. Rockville, MD: Center for SAT, Substance-abuse and Mental Health Services Administration.

Green, B. L., Furrer, C., \& McAllister, C. (2007). How do relationships support parenting? Effects of attachment style and social support on parenting behavior in an at-risk population. American Journal of Community Psychology, 40, 96-108.

Green, B. L., Rockhill, A., \& Furrer, C. (2007). Does substance abuse treatment make a difference for child welfare case outcomes? A statewide longitudinal analysis. Children and Youth Services Review, 29, 460-473.

Gregoire, K. A., \& Schultz, D. J. (2001). Substance-abusing child welfare parents: Treatment and child placement outcomes. Child Welfare, $L X X X, 433-452$.

Grella, C. E., \& Greenwell, L. (204). Substance abuse treatment for women: Changes in setting where women received treatment and types of services provided, 1987-1998. Journal of Behavioral Health Services \& Research, 31, 367-383.

Grella, C. E., Hser, Y. I., \& Huang, Y. C. (2006). Mothers in substance abuse treatment: Differences in characteristics based on involvement with child welfare services. Child Abuse \& Neglect, 30, 55-73.

Hayward, R. A., \& DePanfilis, D. (2007). Foster children with an incarcerated parent: Predictors of reunification. Children and Youth Services Review, 29, 1320-1334.

Hershkowitz, I., Lamb, M. E., \& Horowitz, D. (2007). Victimization of children with disabilities. American Journal of Orthopsychiatry, 77, 629-635.

Hill, R. B. (2007). An analysis of racial/ethnic disproportionality and disparity at the national, state, and county levels. Washington, DC: Casey-CSSP Alliance for Racial Equity in Child Welfare.

Jansson, L. M., Svikis, D. S., \& Beilenson, P. (2003). Effectiveness of child case management services for offspring of drug dependent women. Substance Use \& Misuse, 38, 1933-1952.

Johnson, E. I., \& Waldfogel, J. (2002). Parental incarceration: Recent trends and implications for child welfare. Social Service Review, 76, 460-479.

Jones, L. (2005). The prevalence and characteristics of substance abusers in a child protective service sample. Journal of Social Work Practice in the Addictions, 4, 33-50.

Kantor, G. K., \& Little, L. (2003). Defining the boundries of child neglect: When does domestic violence equate with parental failure to protect? Journal of Interpersonal Violence, 18, 338-355. 
Kapp, S. (2001). The path to adoption for children of color. Child Abuse \& Neglect, 25, 215.

Karoll, B., \& Poertner, J. (2002). Judges', caseworkers', and substance abuse counselors' indicators of family reunification with substance-affected parents. Child Welfare, 81, 249-269.

Kessler, R. C., Crum, R. M., Warner, L. A., Nelson, C. B., Schulenberg, J., \& Anthony, J. C. (1997). Lifetime co-occurrence of DSM-III-R alcohol abuse and dependence with other psychiatric disorders in the National Comorbidity Survey. Archives of General Psychiatry, 54, 313-321.

Kotchick, B.A., Dorsey, S., \& Heller, L. (2005). Predictors of parenting among African-American single mothers: Personal and contextual factors. Journal of Marriage and Family, 67, 448-460.

Kohl, P. L., Edleson, J. L., English, D. J., \& Barth, R. P. (2006). Domestic violence and pathways into child welfare services: Findings from the National Survey of Child and Adolescent Well-Being. Children and Youth Services Review, 27, 1167-1182.

Larsen, J., (2000). Court strategies under ASFA to help substance-using families recover. Juvenile and Family Court Journal, 51, 1-8.

Lemon, N. K. D. (1999). The legal system's response to children exposed to domestic violence. The Future of Children, 9, 67-82.

Lu, Y. E., Landsverk, J., Ellis-Macleod, E., Newton, R., Ganger, W., \& Johnson, I. (2004). Race, ethnicity, and case outcomes in child protective services. Children and Youth Services Review, 26, 447-461.

Magura, S., \& Laudet, A. B. (1996). Parental substance abuse and child maltreatment: Review and implications for intervention. Children and Youth Services Review, 18, 193-220.

Maluccio, A. N., \& Ainsworth, F. (2003). Drug use by parents: A challenge for family reunification practice. Children \& Youth Services Review, 25, 511-533.

Marcenko, M. 0., Kemp, S. P., \& Larson, N. C. (2000). Childhood experiences of abuse, later substance use, and parenting outcomes among low-income mothers. American Journal of Orthopsychiatry, 70, 316-326.

McAlpine, C., Marshall, C. C., \& Doran, N. H. (2001). Combining child welfare and substance abuse services: A blended model of intervention. Child Welfare, LXXX, 129-149.

McConnell, D., \& Llewellyn, G. (2000). Disability and discrimination in statutory child protection proceedings. Disability \& Society, 15, 883-895.

McMillen, J., Scott, L., Zima, B., Ollie, M., Munson, M., \& Spitznagel, E. (2004). Use of mental health services among older youths in foster care. Psychiatric Services, 55, 811-817.

Meyer, A. S., McWey, L. M., McKendrick, W., \& Henderson, T. L. (2010). Substance using parents, foster care, and termination of parental rights: The importance of risk factors for legal outcomes. Children and Youth Services Review, 32, 639-649.

Miller, N. S., \& Flaherty, J. A. (2000). Effectiveness of coerced addiction treatment (alternative consequences): A review of the clinical research. Journal of Substance-abuse Treatment, 18, 9-16.

Mowbray, C. T., Oyserman, D., \& Ross, S. (1995). Parenting and the significance of children for women with a serious mental illness. Journal of Mental Health Administration, 22, 189-200.

National Center on Addiction and Substance Abuse at Columbia University. (2005). Family matters: Substance abuse and the American family. New York: Author. Retrieved December 16, 2013, from http://www.casacolumbia.org/Absolutenm/articlefiles/380family_matters_report.pdf
Noonan, K., \& Burke, K. (2005). Termination of parental rights: Which foster care children are affected? The Social Science Journal, 42, 241-256.

O'Flynn, M. (1999). The Adoption and Safe Families Act of 1997: Changing child welfare policy without addressing parental substance abuse. Journal of Contemporary Health Law \& Policy, 16, 243-271.

0'Toole, T. P., Freyder, P. J., Gibbon, J. L., Hanusa, B. J., Selzer, D., \& Fine, M. J. (2004). ASAM Patient Placement Criteria treatment levels: Do they correspond to care actually received by homeless substance abusing adults? Journal of Addictive Diseases, 23, 1-15.

Osofsky, J. D. (2003). Prevalence of children's exposure to domestic violence and child maltreatment: Implications for prevention and intervention. Clinical Child and Family Psychology Review, 6, 161-170.

Peters, R. H., Greenbaum, P. E., Edens, J. F., Carter, C. R., \& Ortiz, M. M. (1998). Prevalence of DSM-IV substance abuse and dependence disorders among prison inmates. American Journal of Drug \& Alcohol Abuse, 24, 573-587.

Raudenbush, S., \& Bryk, A. (2002). Hierarchal linear models: Applications and data analysis methods (2nd ed). Chicago: Sage Publications.

Risley-Curtiss, C., Stromwall, L. K., Hunt, D. T., \& Teska, J. (2004). Identifying and reducing barriers to reunification for seriously mentally ill parents involved in child welfare cases. Families in Society: The Journal of Contemporary Social Services, 85, 107-118.

Rittner, B., \& Dozier, C. D. (2000). Effects of court-ordered substance-abuse treatment in child protective services. Social Work, 45, 131-140.

Ryan, J. P., Choi, S., Hong, J. S., Hernandez, P., \& Larrison, C. R. (2008). Recovery coaches and substance exposed births: An experiment in child welfare. Child Abuse and Neglect, 32, 10721079.

Sagatun-Edwards, I. J., Saylor, C., \& Shifflett, B. (1995). Drug exposed infants in the social welfare system and juvenile court. Child Abuse \& Neglect, 19, 83-91.

Schneider, K. M., \& Phares, V. (2005). Coping with parental loss because of termination of parental rights. Child Welfare, LXXXIV, 819-842.

Semidei, J., Radel, L. F., \& Nolan, C. (2001). Substance abuse and child welfare: Clear linkage and promising responses. Child Welfare, $L X X X, 109-128$.

Seymour, C., \& Finney-Hairston, C. (2001). Children with parents in prison: Child welfare policy, program, and practice issues. Piscataway, NJ: Transaction Publishers.

Shelton, J. W. C., \& Smith, G. D. (1990). Termination of parental rights: A juvenile judge's toughest decision gets tougher when the question involves the mentally ill parent. Children's Legal Rights Journal, 11, 24-36.

Sidebotham, P., Golding, J., \& The ALSPAC Study Team. (2001). Child maltreatment in the "Children of the Nineties": A longitudinal study of parental risk factors. Child Abuse \& Neglect, 25, 1177-1200.

Smith, B. D. (2003). How parental drug use and drug treatment compliance related to family reunification. Child Welfare, 82, 335365.

Smith, B. D., \& Marsh, J. C. (2002). Client-service matching in substance-abuse treatment for women with children. Journal of Substance-abuse Treatment, 22, 161-168. 


\section{HONG, ET AL. TERMINATION OF PARENTAL RIGHTS FOR PARENTS WITH SUBSTANCE ABUSE DISORDER}

Smith, D. K., Johnson, A. C., Pears, K. C., Fisher, P. A., \& DeGarmo, D. S. (2007). Child maltreatment and foster care: Unpacking the effects of prenatal and postnatal parental substance use. Child Maltreatment, 12, 150-160.

Snyder, Z. K., Carlo, T. A., \& Coats-Mullins, M. M. (2001). Parenting from prison: An examination of a children's visitation program at a women's correctional facility. Marriage \& Family Review, 32, 33-61.

Sobsey, D., Randall, W., \& Parrila, R. K. (1997). Patterns of sexual abuse and assault. Sexuality and Disability, 9, 243-259.

Steinhauer, P. D. (1991). The least detrimental alternative: $A$ systemic guide to case planning and decision making for children in care. Toronto: University of Toronto Press.

Suchman, N., Mayes, L., Conti, J., Slade, A., \& Rounsaville, B. (2004). Rethinking parenting interventions for drug-dependent mothers: From behavioral management to fostering emotional bonds. Journal of Substance Abuse Treatment, 27, 179-185.

Sun, A. -P., Shillington, A. M., Hohman, M., \& Jones, L. (2001). Caregiver AOD use, case substantiation, and AOD treatment: Studies based on two Southwestern counties. Child Welfare, LXXX, 151177.

Tyler, R., Howard, J., Espinosa, M., \& Doakes, S. S. (1997). Placement with substance-abusing mothers vs. placement with other relatives: Infant outcomes. Child Abuse \& Neglect, 21, 337-349.

U.S. Department of Health and Human Services (1999a). National survey of child and adolescent well-being (NCSAW): CPS sample component wave 1 data analysis report. Washington, DC: Administration for Children and Families.

U.S. Department of Health and Human Services (1999b). Blending perspectives and building common ground: $A$ report to Congress on substance abuse and child protection. Retrieved September 3, 2010, from http://aspe.hhs.gov/HSP/subabuse99/subabuse.htm.

U.S. Department of Health and Human Services (2008). Trends in foster care and adoption. Retrieved September 7, 2010, from http::www.acf.hhs.gov/programs/cb/stats_research/afcars/trends.htm I.

U.S. Department of Health and Human Services (n.d.). Report to Congress on adoption and other permanency outcomes for children in foster care: Focus on older children. Retrieved, June 1, 2009, from http://www.acf.hhs.gov/programs/cb/pubs/congress_adopt/challenges. htm

U.S. Department of Justice (1997). Correctional populations in the United States, 1995. Washington, D.C.: Author.

U.S. General Accounting Office (1994). Foster care: Parental drug abuse has alarming impact on children. GA0/HEHS-94-89. Washington, DC: General Accounting Office.

Vogel, C. A. (1999). Using administrative databases to examine factors affecting length of stay in substitute care. Children and Youth Services Review, 21, 677-690.

Walsh, C., MacMillan, H. L., \& Jamieson, E. (2003). The relationship between parental substance abuse and child maltreatment: Findings from the Ontario Health Supplement. Child Abuse \& Neglect, 27, 1409-1425.

Wattenberg, E., Kelley, M., \& Kim, H. (2001). When the rehabilitation ideal fails: A study of parental rights termination. Child Welfare, LXXX, 405-431.

Wekerle, C., Wall, A. M., Leung, E., \& Trocme, N. (2007). Cumulative stress and substantiated maltreatment: The importance of caregiver vulnerability and adult partner violence. Child Abuse \& Neglect, 31, 427-443.
Wheeler, M. M., \& Fox, C. L. (2006, June). Family dependency treatment court: Applying the drug court model in child maltreatment cases. Drug Court Practitioner Fact Sheet, 5, 1-6.

Wulczyn, F. (2003). Closing the gap: Are changing exit patterns reducing the time African American children spend in foster care relative to Caucasian children? Children and Youth Services Review, 25, 431-462.

Wulczyn, F., Hislop, K., \& George, R. (2000). An update from the multi-state foster care data archive: Foster care dynamics 19831999. Chicago, IL: Chapin Hall Center for Children, University of Chicago.

Wulczyn, F., \& Lery, B. (2007). Racial disparity in foster care admissions. Chicago, IL: Chapin Hall Center for Children, University of Chicago.

Young, N. K., Gardner, S., \& Dennis, K. (1998). Responding to alcohol and other drug problems in child welfare: Weaving together practice and policy. Washington, D.C.: Child Welfare Press.

Zinn, A. E., \& Slowriver, J. (2008). Expediting permanency: Legal representation for foster children in Palm Beach County. Chicago, IL: Chapin Hall Center for Children at the University of Chicago. 